$$
\begin{gathered}
1 N-24 \\
2598 \\
3 \times P
\end{gathered}
$$

NASA Technical Memorandum 109026

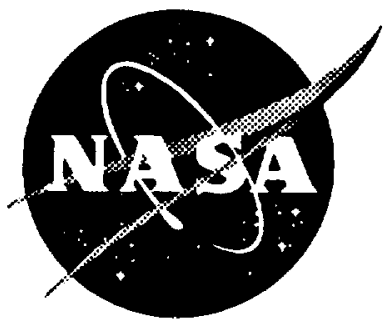

\title{
Prediction of Stress-Strain Response of SCS-6/Timetal-21S Subjected to a Hypersonic Flight Profile
}

M. Mirdamadi

Analytical Services and Materials, Inc., Hampton, Virginia

W. S. Johnson

Langley Research Center, Hampton, Virginia

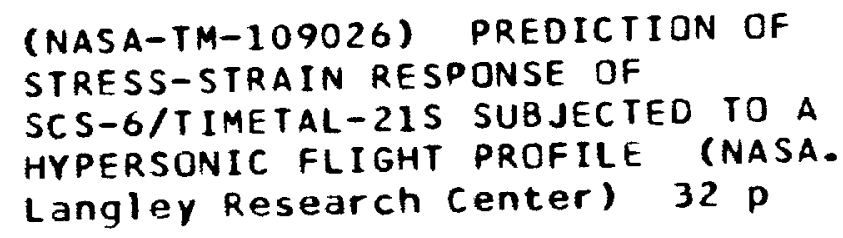

N94-28823

February 1994

$G 3 / 24 \quad 0002598$

National Aeronautics and

Space Administration

Langley Research Center

Hampton, Virginia 23681-0001 


\title{
Prediction of Stress-Strain Response of SCS-6/Timetal-21S Subjected to a Hypersonic Flight Profile
}

\author{
M. Mirdamadi' and W. S. Johnson²
}

Thermomechanical response of a cross-ply SCS-6/Timetal-21S composite subjected to a generic hypersonic flight profile with the temperature ranging from $-130^{\circ} \mathrm{C}$ to $816^{\circ} \mathrm{C}$ was evaluated experimentally and analytically. A two dimensional micromechanical analysis, VISCOPLY, was used to predict the stress-strain response of the laminate and of the constituents in each ply during thermomechanical loading conditions. In the analysis, the fiber was modeled as elastic with transverse orthotropic and temperature dependent properties and the matrix was modeled using a thermo-viscoplastic constitutive relation. The fiber transverse modulus was reduced in the analysis to simulate fiber-matrix interface failure. Reasonable agreement was found between measured and predicted laminate stress-strain response when fiber-matrix debonding was modeled.

\section{INTRODUCTION}

Titanium matrix composites (TMC) reinforced with continuous silicon fibers are being considered as structural materials for elevated temperature applications in future generation hypersonic vehicles. In such applications, TMC components will be subjected to complex flight profiles consisting of fatigue loading cycles, creep-fatigue loading cycles, and thermomechanical fatigue (TMF) loading at various elevated temperatures. Due to the large differences in the thermal and mechanical properties of the fiber and the matrix, significant thermal residual stresses are developed in the composite. The resulting stress coupled with applied thermal and mechanical loading, can lead to a complex state of stress in these composites. In order to develop life prediction methodologies for TMC, one must be able to predict the stresses and strains that occur in the constituents of the composite during the complicated TMF loading profiles. Therefore, a micromechanical based analyses, that can account for viscoplastic behavior of the both fiber and matrix, are very attractive and helpful in establishing a framework for a life prediction methodology.

In recent studies $[1,2]$, such a micromechanics based analysis was used to predict the stress-strain response of a unidirectional SCS-6/Ti-15-3 composite subjected to the inphase and out-of-phase TMF loading and a cross-ply SCS-6/Ti-15-3 composite subjected to a TMF flight profile. Good agreement between experimental results and predictions was found. The analysis also described the complex global behavior of the composite and the local behavior of the constituents subjected to TMF loading conditions.

\footnotetext{
'Rescarch Scientist, Analytical Services and Matcrials Inc., Hamplon, VA 23666.

${ }^{2}$ Senior Research Scientist, NASA Langlcy Research Center, Hampton, VA 23681.
} 
The objective of this research is to experimentally determine the global stress-strain response of a [0/90] ${ }_{2 \mathrm{~s}}$ SCS-6/Timetal-21S composite subjected to a generic hypersonic flight profile with the temperature ranging from $-130^{\circ} \mathrm{C}$ to $816^{\circ} \mathrm{C}$ and to analytically predict the measured global laminate stress-strain response. The analysis also included fiber-matrix interface failure.

\section{ANALYTICAL METHOD - VISCOPLY}

A two dimensional micromechanical model, and the associated computer code (VISCOPLY), was used to predict the stress-strain response of the composite. The VISCOPLY code, developed by Bahei-El-Din, uses the vanishing fiber diameter (VFD) model [3] to calculate the orthotropic properties of a ply. The ply properties are then used in a laminated plate theory [4] to predict the overall laminate response. Both the fiber and the matrix can be described as a thermo-viscoplastic material.

The viscoplastic constitutive model implemented in the VISCOPLY program was developed by Bahei-El-Din, Shah and Dvorak [5] for high temperature, isothermal and nonisothermal, applications and is based on the viscoplastic theory of Eisenberg and Yen [6]. This constitutive viscoplastic model assumes the existence of an equilibrium stressstrain response which corresponds to the theoretical lower bound of the dynamic response. In addition, this constitutive viscoplastic model assumes that the elastic response is rate-independent and that inelastic rate-dependent deformation takes place if the current stress state is greater than the equilibrium stress. The inelastic strain rate is described using a power law function of overstress [7] which is defined as the difference between the current stress and the equilibrium stress. Under tensile loading condition, this inelastic strain rate can be written as;

$$
\dot{\varepsilon}_{\text {in }}=k\left(\sigma-\sigma^{*}\right)^{p}
$$

where $\sigma$ is the current stress, $\sigma^{*}$ is the equilibrium stress, and $k$ and $p$ are the material constants. The material constants, $k$ and $p$, are needed to describe the viscoplastic response for a given temperature. When isotropic hardening and thermal recovery effects are not significant, these parameters can be determined from two monotonic uniaxial tests. Determination of the viscoplastic material constants is presented in the Experimental Techniques section of this paper.

Complex combinations of thermal and mechanical loads can be readily modeled using the VISCOPLY program. Sequential jobs can be run to vary the order and rate of load and temperature. Fiber and matrix average stresses and strains and the overall composite response under thermomechanical loading conditions are calculated. Due to the assumptions made in the of VFD model, local micromechanical effects such as the lateral constraint of the matrix due to the presence of the fibers and stress concentrations in the 
fibers and matrix are not accounted for in the VISCOPLY program. Nevertheless, the VISCOPLY program has been used to predict the global thermomechanical response within $10 \%$ of the experimental results in similar TMC $[1,2]$.

Fiber-matrix interface failure in TMC occurs early under applied load and causes significant changes in the global stress-strain response [8] and must be accounted for in any analysis. Experimental data [8] showed that the failure of the fiber-matrix interface corresponds to a distinct knee in the stress-strain curve. Previous work [2] on [0/90] $2 \mathrm{~s}$ SCS-6/Ti-15-3 composites showed that the fiber-matrix interface failure can be simulated by reducing the fiber transverse modulus, $E_{t}^{f}$, in the $90^{\circ}$ plies at the stress level corresponding to the observed knee in the stress-strain curve of the $[0 / 90]_{2 s}$ laminate at room temperature. In elevated temperature fatigue tests, thermal residual stresses were relieved and no knee was apparent in the stress-strain response. It was therefore assumed that, for temperatures above $400^{\circ} \mathrm{C}$, the fiber-matrix interfacial failure occurred upon loading and the fiber transverse modulus in the $90^{\circ}$ plies was reduced at the start of loading [2]. It was found [2] that by multiplying the fiber transverse modulus of the $90^{\circ}$ plies by $0.1\left(E_{t}^{f} / E_{a}^{f}=0.1\right.$, where $E_{a}^{f}$ is the fiber axial modulus) gave the best overall fit to the experimental data as shown in the Figure 1. This factor will be used in all predictions of the $[0 / 90]_{2 \mathrm{~s}}$ SCS-6/Timetal-21S composite to simulate fiber-matrix interface failure.

\section{MATERIAL AND TEST SPECIMENS}

The material used in this study was SCS-6/Timetal-21S which was fabricated into a $[0 / 90]_{2 s}$ laminate by hot isostatic pressing (HIPing) Ti-15Mo-3Nb-3 Al-0.2Si foil between tapes of unidirectional SCS-6 silicon-carbide fibers having a diameter of $0.14 \mathrm{~mm}$. The fibers were held in place with $\mathrm{Ti}-\mathrm{Nb}$ crossweave wires. An average volume fraction of 0.365 was measured for this laminate.

Rectangular specimens having a length of $152 \mathrm{~mm}$, width of $12.7 \mathrm{~mm}$ and thickness of $1.69 \mathrm{~mm}$, were machined using a diamond wheel saw. Brass tabs $(10 \mathrm{~mm} \times 30 \mathrm{~mm} \times 1$ $\mathrm{mm}$ ) were placed between the end of the specimen and the grips to avoid specimen failure in the grips. Prior to testing, each specimen was heat treated (aged) at $621^{\circ} \mathrm{C}$ for eight hours in vacuum to stabilize matrix material.

\section{EXPERIMENTAL TECHNIQUES}

All the experiments were conducted using a $100-\mathrm{kN}$ closed-loop servohydraulic test frame equipped with water-cooled hydraulic grips. In addition, the test frame was equipped with a load profiler capable of running predetermined strain or load profiles. The test specimen was heated using a $5-\mathrm{kW}$ induction generator with three independent adjustable coils such as developed by Ellis and co-workers [9]. The induction generator was controlled by a temperature profiler capable of running predetermined temperature 
profiles. K-type thermocouples were used to monitor and control the temperature along a 50-mm gage length section in the center of the specimen. In addition, an infrared thermovision camera was used to insure that a uniform temperature distribution was achieved along the gage section of the specimen. Axial strains were measured on the edge of the specimen using a high temperature, quartz rod water-cooled extensometer with a 25-mm gage length. An eight channel analog-digital PC based data acquisition system was used to record and store the test data in terms of stress, strain, and temperature as a function of time.

\section{Isothermal - Matrix Characterization}

The matrix material constants needed for input by the VISCOPLY program are given in Table 1. These material constants include coefficient of thermal expansion (CTE), elastic modulus $(E)$, yield stress $(Y)$, equilibrium stress-strain curve parameters ( $A$ and $n$ ), and viscoplastic parameters ( $k$ and $p)$, for a given temperature. CTE was determined from the results of a load-controlled experiment. The CTE test specimen, under zero load, was subjected to temperature increments ranging from $-130^{\circ} \mathrm{C}$ to $816^{\circ} \mathrm{C}$. At each increment, the temperature was held constant (about 1 minute) to allow for stabilization. The temperatures and the corresponding thermal strains were fitted to a third degree polynomial using method of least squares as shown in Figure 2. The resulting polynomial function was differentiated with respect to temperature to determine CTE as a function of temperature. The elastic modulus $(\mathrm{E})$ and the yield stress $(\mathrm{Y})$ were determined from the linear portion and onset of nonlinearity of the stress-strain curve at each temperature of interest, respectively.

To define the equilibrium stress-strain curve, strain-controlled tests were conducted with 5-minute hold-periods imposed at predetermined strain levels to allow stress relaxation to occur. The strain-rate during loading was $1 \times 10^{-4} \mathrm{~mm} / \mathrm{mm}$ per second. Duration of holdperiod and strain-rate were chosen based on previous work on similar TMC [2]. These tests were similar in approach to those outlined by Eisenberg and Yen [6] and are schematically shown in Figure 3. At each temperature, a minimum of five strain levels were selected to construct the equilibrium stress-strain curve. The equilibrium curve was then approximated by fitting to a power law equation,

$$
\sigma^{*}=A\left(\varepsilon_{\text {in }}\right)^{\mathbf{n}}
$$

using the method of least squares, to the observed values of the stress at the ends of hold periods and corresponding inelastic strain $\left(\varepsilon_{i n}\right)$ determined from the following equation,

$$
\varepsilon_{\text {in }}=\varepsilon_{\mathrm{t}}-\sigma^{*} / \mathrm{E}
$$

where $\varepsilon_{t}$ is the known predetermined total strain value. The curve fitting parameters $A$ and $\mathrm{n}$ in $\mathrm{Eq}(2)$ are given in Table 1 
The load-controlled monotonic tests used to determine the rate-dependent deformation were conducted at a constant stress-rate of $2.56 \mathrm{MPa}$ per second. The stress-rate was chosen based on previous work on similar TMC [2]. Given the equilibrium curve, the overstress can be determined as illustrated in Figure 4a. To facilitate the numerical manipulation, the stress $(\sigma)$ and corresponding inelastic strain values $\left(\varepsilon_{\text {in }}\right)$ determined from the load-controlled test were also fit to a power law equation

$$
\sigma=\mathrm{C}\left(\varepsilon_{\mathrm{in}}\right)^{\mathrm{m}}
$$

using the method of least squares. The strain value $\left(\varepsilon_{\text {in }}\right)$ was calculated similar to Equation (3) except $\sigma^{*}$ is replaced by $\sigma$, the current stress. $C$ and $\mathrm{m}$ are curve fitting parameters. The resulting equation was differentiated with respect to time as follows,

$$
\dot{\sigma}=\frac{d \sigma}{d t}=\frac{d \sigma}{d \varepsilon_{i n}} \cdot \frac{d \varepsilon_{i n}}{d t}=\frac{d \sigma}{d \varepsilon_{i n}} \dot{\varepsilon}_{i n}
$$

By substituting Equation (4) into Equation (5) and rearranging, the inelastic strain rate can be written as,

$$
\dot{\varepsilon}_{\text {in }}=\frac{\dot{\sigma}}{\mathrm{Cm}}\left(\varepsilon_{\mathrm{in}}\right)^{1-\mathrm{m}}
$$

Knowing the stress-rate $(\dot{\sigma}=2.56 \mathrm{MPa} / \mathrm{Sec})$ and the curve fitting parameters $\mathrm{C}$ and $\mathrm{m}$, from Equation (4), the inelastic strain rate $\left(\dot{\varepsilon}_{\text {in }}\right)$ can be calculated from Equation (6) for a given inelastic strain. The viscoplastic material constants $(k$ and $p)$ were then determined by fitting a power law equation (Equation (1) to the inelastic strain rate (Equation (6)) and overstress $\left(\sigma-\sigma^{*}\right)$, determined from Equations (2) and (4), using method of least squares technique as illustrated in Figure $4 \mathrm{~b}$. The material constants needed for input by the VISCOPLY program are summarized in Table 1, the material parameters constants C and $\mathrm{m}$ are not directly needed for input by the VISCOPLY program so are subsequently not listed in Table 1 .

\section{TMF test setup}

A TMF test capability developed previously [2] was modified to conduct a generic hypersonic flight profiles such as shown in Figures $5 \mathrm{a}$ and $5 \mathrm{~b}$. As indicated in the figures the flight profile consisted of Mission I and Mission II. The letters shown in Figures 5a and $5 \mathrm{~b}$ will be used later for comparison with the stress-strain results. The entire TMF flight profile shown in Figure 5a is applied 24 times followed by the TMF flight profile shown in Figure $5 \mathrm{~b}$ once. This sequence is repeated until the failure of the test specimen. The temperature profiles shown in Figures $5 \mathrm{a}$ and $5 \mathrm{~b}$ are the same with a maximum and 
minimum applied temperature of $815^{\circ} \mathrm{C}$ and $-130^{\circ} \mathrm{C}$, respectively. The heating and cooling rates of the temperature profile are $2.8^{\circ} \mathrm{C} / \mathrm{sec}$ and $1.4^{\circ} \mathrm{C} / \mathrm{sec}$, respectively. The loading profiles in Figures $5 \mathrm{a}$ and $5 \mathrm{~b}$ have slight differences. In Figure $5 \mathrm{a}$, the maximum applied stress in the loading profile is $336 \mathrm{MPa}$, while the maximum applied stress in Figure $5 \mathrm{~b}$ is $420 \mathrm{MPa}$. In addition, Figure $5 \mathrm{~b}$ contains the segment of the loading profile designated as d-e-f which is in-phase with the applied temperature. The mechanical fatigue cycles are applied at a frequency of $1 \mathrm{~Hz}$. In all the TMF test experiments, the test specimen was subjected to thermal loading history prior to mechanical loading. This step was necessary to assure precise synchronization between the applied temperature and the mechanical load signals.

Details of the TMF test setup are given in [2]. Briefly, the TMF test setup consists of a 100-kN, closed-loop, servohydraulic test frame equipped with water-cooled hydraulic grips, a load profiler, a $5-\mathrm{kW}$ induction generator controlled by a temperature profiler, and a nitrogen supply tank. The temperature profiler was interfaced with the load profiler to initiate the temperature spectrum at any desired segment in the load profile. This assures precise synchronization between mechanical and thermal loading profiles. In addition, the temperature profiler was modified so that the cryogenic temperatures (as low as $-130^{\circ} \mathrm{C}$ ) could be controlled. The nitrogen supply tank was modified to supply gaseous or liquid nitrogen, depending on the required cooling rate. The flow of gaseous and liquid nitrogen was controlled by the temperature profiler during the cool down portion of the temperature profile. The combined use of gaseous and liquid nitrogen with induction heating was necessary to maintain the desired cooling rate of $1.4^{\circ} \mathrm{C} / \mathrm{sec}$ and to reached the minimum temperature of $-130^{\circ} \mathrm{C}$.

\section{RESULTS AND DISCUSSIONS}

In this section, the constituent properties are presented, the isothermal neat Timetal-21S matrix behavior is analyzed using VISCOPLY and compared with observed experimental behavior. Experimental data and VISCOPLY predictions of the stress-strain response of a $[0 / 90]_{2 \mathrm{~s}}$ SCS-6/Timetal-2IS composite subjected to a generic hypersonic flight profile are presented and compared.

\section{Constituent Properties}

The temperature dependent thermal and mechanical properties of the fiber used in this study are shown in Table 2 [11]. In the analysis, the fiber was assumed to remain elastic with transverse orthotropic properties. The temperature-dependent and rate-dependent material properties of the neat Timetal-21S matrix were determined from tests of the matrix material conducted at room temperature and elevated temperatures of $316^{\circ} \mathrm{C}$, $427^{\circ} \mathrm{C}, 482^{\circ} \mathrm{C}, 566^{\circ} \mathrm{C}, 621^{\circ} \mathrm{C}, 650^{\circ} \mathrm{C}, 704^{\circ} \mathrm{C}$, and $760^{\circ} \mathrm{C}$ and are given in Table 1. Values from Table 1 will be used for all predictions shown here-in. 


\section{Timetal-21S Matrix Behavior}

To verify the accuracy of the material constants for the Timetal-21S matrix (Table 1), the analytical predictions were compared to experimental data from the literature tests [12] and the present study of the Timetal-21-S matrix that were conducted under strain control at different temperatures.

The cyclic stress-strain response of the neat Timetal-21S at $650^{\circ} \mathrm{C}$ with a strain rate of $83.3 \times 10^{-6} / \mathrm{sec}$ and at $760^{\circ} \mathrm{C}$ with the strain rates of $83.3 \times 10^{-6} / \mathrm{sec}$ and $833.3 \times 10^{-6} / \mathrm{sec}$ are shown in Figures 6,7 , and 8 , respectively [5]. The tests were conducted at an applied total strain range of $\pm 1 \%$. As seen in the figures VISCOPLY accurately predicted the cyclic stress-strain response of the Timetal-21S using only the material constants (determined under tensile loading conditions) shown in Table 1.

The time-dependent response of the neat Timetal-21S at $760^{\circ} \mathrm{C}$, determined from the cyclic stress-relaxation test, is shown in Figure 9. The strain rate during loading was $1 \times 10^{-4} / \mathrm{sec}$ with a 300 second hold-time applied at the pre-determined strain levels of $0.0025,0.005,0.0075,0.01,0.015$, and 0.02 . Also shown in the figure is the VISCOPLY prediction. As seen in the figure VISCOPLY accurately predicted the maximum stress and the initial portion of the stress relaxation response. However, the experimentally observed stresses at the end of the hold periods were lower than the VISCOPLY prediction (see Figure 10) which may be due to the isotropic hardening and thermal recovery effects which are not accounted for in the VISCOPLY program.

\section{Laminate Behavior}

A thermal response test on the cross-ply laminate was conducted by applying only the thermal history of the flight profile shown in Figure 5. The measured thermal strains and the VISCOPLY predictions are shown in Figure 10. As seen in the figure, thermal strain of the laminate was accurately predicted by the VISCOPLY program and the constituents material properties shown in Tables 1 and 2.

The test specimen was then subjected to the full thermal and mechanical flight profiles shown in Figure 5a and Figure 5b. The horizontal segments of the experimental data indicate an increase in strain due to temperature change while the mechanical load was held constant. The experimental data of the 1st, 5th, and 25th flights are shown in Figures 11 through 13. For clarity, different symbols have been used for Mission I and Mission II. Also shown in the figures are the VISCOPLY predictions with the simulated failure of the fiber-matrix interface of the $90^{\circ}$ plies. The letters placed at various locations on the stress-strain response can be referenced back to Figure 5 to find the associated segment on the flight profile. The predictions of the cyclic load, at point $\mathrm{K}$ and $\mathrm{S}$, appear broad because the temperature was changing. As seen in Figure 11, VISCOPLY reasonably predicted the observed experimental stress-strain response of the 1st flight. However, a larger permanent strain was observed experimentally (as noted in the figure) 
than was prodicted using VISCOPLY, indicating that other types of damage (such as local plasticity) are occurring which are not accounted for in the VISCOPLY analysis. The experimental stress-strain response stabilized rather quickly (after 2 flights). However, VISCOPLY predictions did not stabilize until the fifth flights. The experimental stress-strain response and of the VISCOPLY prediction of the 5th flight are shown in Figure 12. In the VISCOPLY analysis, the permanent strain observed experimentally during the 5th flight was matched with the strain at start of the analysis. As shown in the figure, the VISCOPLY predicted the stabilized flight stress-strain response reasonably. The experimental stress-strain response of the 25 th flight (using profile shown in Figure $5 b$ ) is shown in Figure 13. Also shown in the figure is the VISCOPLY prediction. As before, the observed permanent strain as a result of flight cycling was incorporated into the VISCOPLY prediction. As seen in the figure, VISCOPLY accurately predicted the observed experimental results.

A second TMF flight profile test was conducted using a portion of the flight profile (portion A-N in Figure 5(a) and a-h in Figure 5(b)) with minimum and maximum applied temperatures of $21^{\circ} \mathrm{C}$ and $816^{\circ} \mathrm{C}$, respectively. The experimental stress-strain response of the 1st, 5th and 25th flights and the VISCOPLY predictions are shown in Figures 1416 , respectively. As before, the letters placed at various locations on the stress-strain response can be referenced back to Figure 5 to find the associated segment on the flight profile. As seen in Figure 14, VISCOPLY predicted the observed experimental stressstrain response reasonably. However, the predicted permanent strain during the 1 st flight was smaller than the experimental observation. As mentioned earlier other types of damage mechanisms (such as local plasticity) are taking place which are not accounted for in the VISCOPLY program. The experimental stress-strain response and of the VISCOPLY prediction of the 5th flight are shown in Figure 15. As mentioned before, the experimentally observed permanent strain was incorporated into the VISCOPLY prediction. As seen in the figure, VISCOPLY accurately predicted the stabilized stressstrain response of the composite subjected to the Mission I of the flight profile. Figure 16 shows the experimental stress-strain response of the composite after 25 flights (using Mission I profile shown in Figure 5b). Also shown in the figure is the VISCOPLY prediction. As before, the observed permanent strain as a result of flight cycling was incorporated into the VISCOPLY prediction. As seen in the figure, VISCOPLY accurately predicted the observed experimental results.

A third TMF test was conducted using a portion of the Mission I of the flight profile shown in Figure 5(b) segments "b" through " $h$ ". The experimental stress-strain response and the VISCOPLY predictions of the first five cycles are shown in Figure 17. As seen in the figure, the experimental stress-strain response stabilized quickly (after cycle 2) while the VISCOPLY prediction did not stabilize until cycle 4 . The VISCOPLY predictions are in excellent agreement with the experimental stress-strain response. The variation of $0^{\circ}$ fiber stress with time for five cycles as predicted by VISCOPLY is shown in Figure 18. As seen in the figure, the maximum fiber stress increases with each subsequent cycle until cycle five. The increase in fiber stress is due to stress relaxation in 
the matrix and subsequent load transferal to the fibers as predicted by the VISCOPLY program.

\section{SUMMARY}

Viscoplastic material response of the neat Timetal-21S matrix was characterized over the temperature range of $21^{\circ} \mathrm{C}$ to $760^{\circ} \mathrm{C}$ and the material constants needed for input into VISCOPLY were determined. VISCOPLY was used to analyze the rate-dependent behavior of the neat Timetal-21S matrix. A micromechanics analysis, VISCOPLY, was used to analyze the stress-strain response of the $[0 / 90]_{2 \mathrm{~s}}$ SCS-6/Timetal-21S composite subjected to the flight profiles. The following conclusions were made:

- VISCOPLY reasonably predicted the cyclic stress-strain response of the neat Timetal-21S matrix at the temperatures of $650^{\circ} \mathrm{C}$ and $760^{\circ} \mathrm{C}$.

- In TMC composite fiber-matrix interface failure must be modeled for accurate predictions. Fiber-matrix interface failures were modeled in the VISCOPLY program by multiplying the transverse modulus of the fiber in the $90^{\circ}$ plies by 0.1 .

- The mechanical response of the composite is rate-dependent at elevated temperatures. VISCOPLY analysis can accurately predict such dependence.

- VISCOPLY accurately predicted the composite stress-strain response for a generic hypersonic flight profile.

\section{ACKNOWLEDGMENT}

This work was done while the first author held a National Research Council (NRC) Research Associateship.

\section{REFERENCES}

[1] Mirdamadi M., and Johnson W. S., "Stress-Strain Analysis of a [0/90 $]_{2 s}$ Titanium Matrix Laminate Subjected to a Generic Hypersonic Flight Profile," NASA TM107584, NASA Langley Research Center, March 1992.

[2] Mirdamadi, M., Johnson, W. S., Bahei-El-Din, Y.A., and Castelli, M. G., "Analysis of Thermomechanical Fatigue of Unidirectional Titanium Metal Matrix Composite," Composite Materials: Fatigue and Fracture, Fourth Volume, ASTM STP 1156, W. W. Stinchcomb and N. E. Ashbaugh Eds., American Society for Testing and Materials, Philadelphia, 1993, pp. 591-607 
[3] Dvorak, G. J. and Bahei-El-Din, Y. A., "Plasticity Analysis of Fibrous Composites," Journal of Applied Mechanics, Vol. 49, 1982, pp. 327-335.

[4] Bahei-El-din, Y. A., "Plasticity Analysis of Fibrous Composite Laminates Under Thermomechanical Loads," Thermal and Mechanical Behavior of Ceramic and Metal Composites, ASTM STP 1080, J. M. Kennedy, N. H. Moeller, and W. S. Johnson, eds., American Society for Testing and Materials, Philadelphia 1990, pp. 20-39.

[5] Bahei-El-Din, Y. A., Shah, R. S., and Dvorak, G. J., "Numerical Analysis of the Rate-Dependent Behavior of High Temperature Fibrous Composites" AMD, Vol. 118: Mechanics of Composites at Elevated temperatures, S. N. Singhal, W. F. Jones, C. T. Herakovich, and T. Cruse, Eds., 1991, pp. 67-78.

[6] Eisenberg, M. A and Yen, C. F., "A Theory of Multiaxial Anisotropic Viscoplasticity," ASME Journal of Applied Mechanics, Vol. 48, 1981, pp. 276284.

[7] Malvern, L. E., "The Propagation of Longitudinal Waves of Plastic Deformation in a Bar of Material Exhibiting a Strain-Rate Effect," ASME Journal of Applied Mechanics, Vol. 18, 1951, pp. 203-208.

[8] Johnson, W. S., Lubowinski, S. L., and Highsmith, A. L., "Mechanical Characterization of Unnotched $\mathrm{SCS}_{6} / \mathrm{Ti}$-15-3 Metal Matrix Composites at Room Temperature," Thermal and Mechanical Behavior of Metal Matrix and Ceramic Matrix Composites, ASTM STP 1080, J. M. Kennedy, H. H. Moeller, and W. S. Johnson Eds., American Society for Testing and Materials, Philadelphia, 1990, pp. 193-218.

[9] Ellis, J.R. and P.A. Bartolotta, "Adjustable Work Coil Fixture for Facilitating the Use of Induction Heating in Mechanical Testing," NASA TM-102461, NASA Lewis Research Center, June 1989.

[10] Khobaib, M. and Ashbaugh, N. E., "Tensile, Creep, and LCF Behavior of Fiberless Timetal 21 S Alloy," Fatigue 93, Vol. II, May, 1993, pp. 909-914.

[11] Bigelow, C. A., "Thermal Residual Stresses in Silicon-Carbide/Titanium [0/90] Laminate," NASA TM 107649, NASA Langley Research Center, July, 1992. 


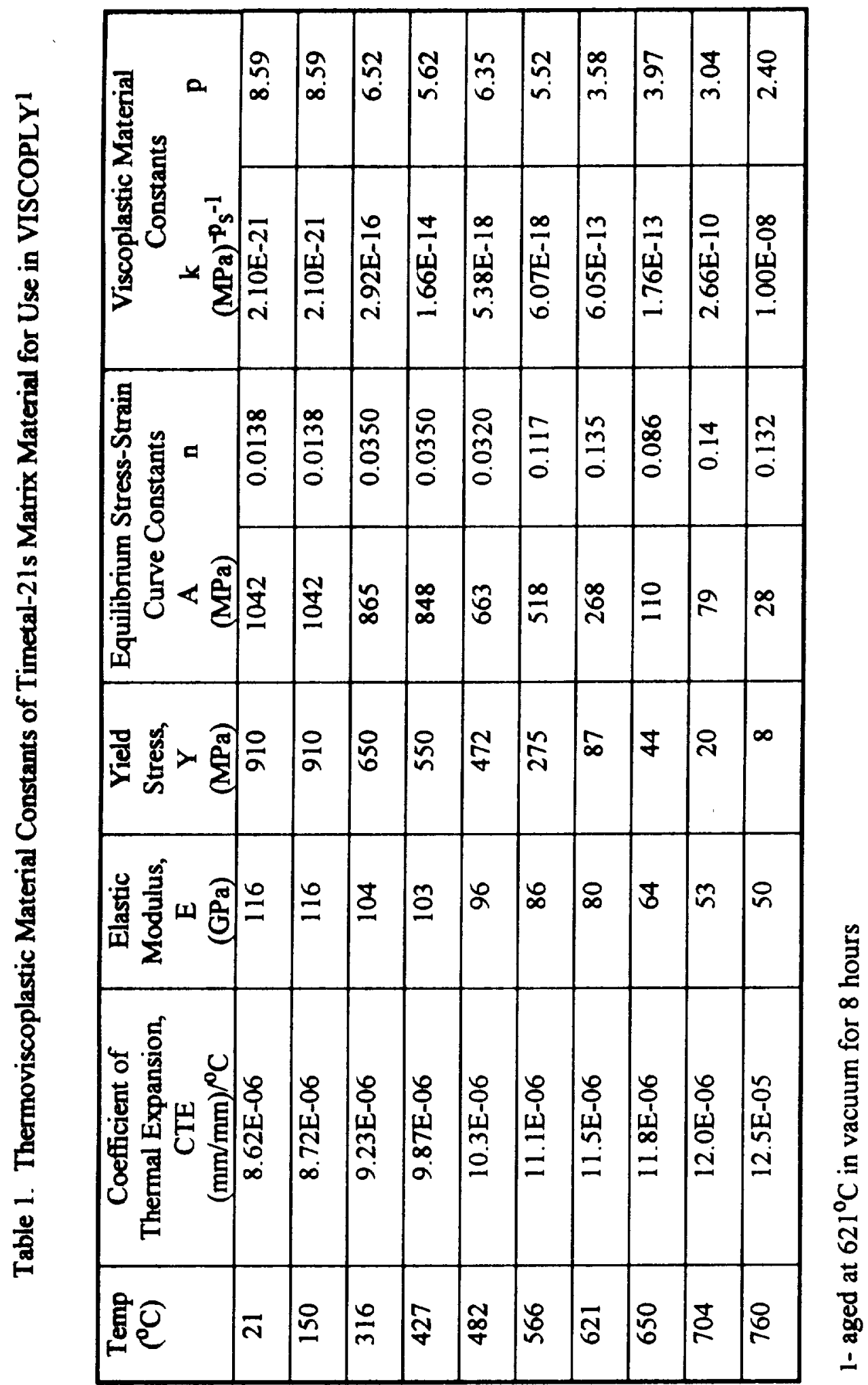


Table 2. Temperature-Dependent Properties of the SCS-6 Fiber [11].

\begin{tabular}{|c|c|c|c|}
\hline Temperature & $\begin{array}{c}\text { Coefficient of } \\
\text { Thermal Expansion } \\
\text { CTE x 10 }\end{array}$ & $\begin{array}{c}\text { Elastic } \\
\text { modulus }\end{array}$ & $\begin{array}{c}\text { Poisson's } \\
\text { ratio }\end{array}$ \\
\hline$\left({ }^{\circ} \mathrm{C}\right)$ & $(\mathrm{mm} / \mathrm{mm}){ }^{\circ} \mathrm{C}$ & $(\mathrm{GPa})$ & \\
\hline 21 & 3.56 & 393 & 0.25 \\
\hline 93 & 3.56 & 390 & 0.25 \\
\hline 204 & 3.62 & 386 & 0.25 \\
\hline 316 & 3.73 & 382 & 0.25 \\
\hline 427 & 3.91 & 378 & 0.25 \\
\hline 538 & 4.1 & 374 & 0.25 \\
\hline 650 & 4.3 & 370 & 0.25 \\
\hline 760 & 4.41 & 365 & 0.25 \\
\hline 871 & 4.57 & 361 & 0.25 \\
\hline
\end{tabular}




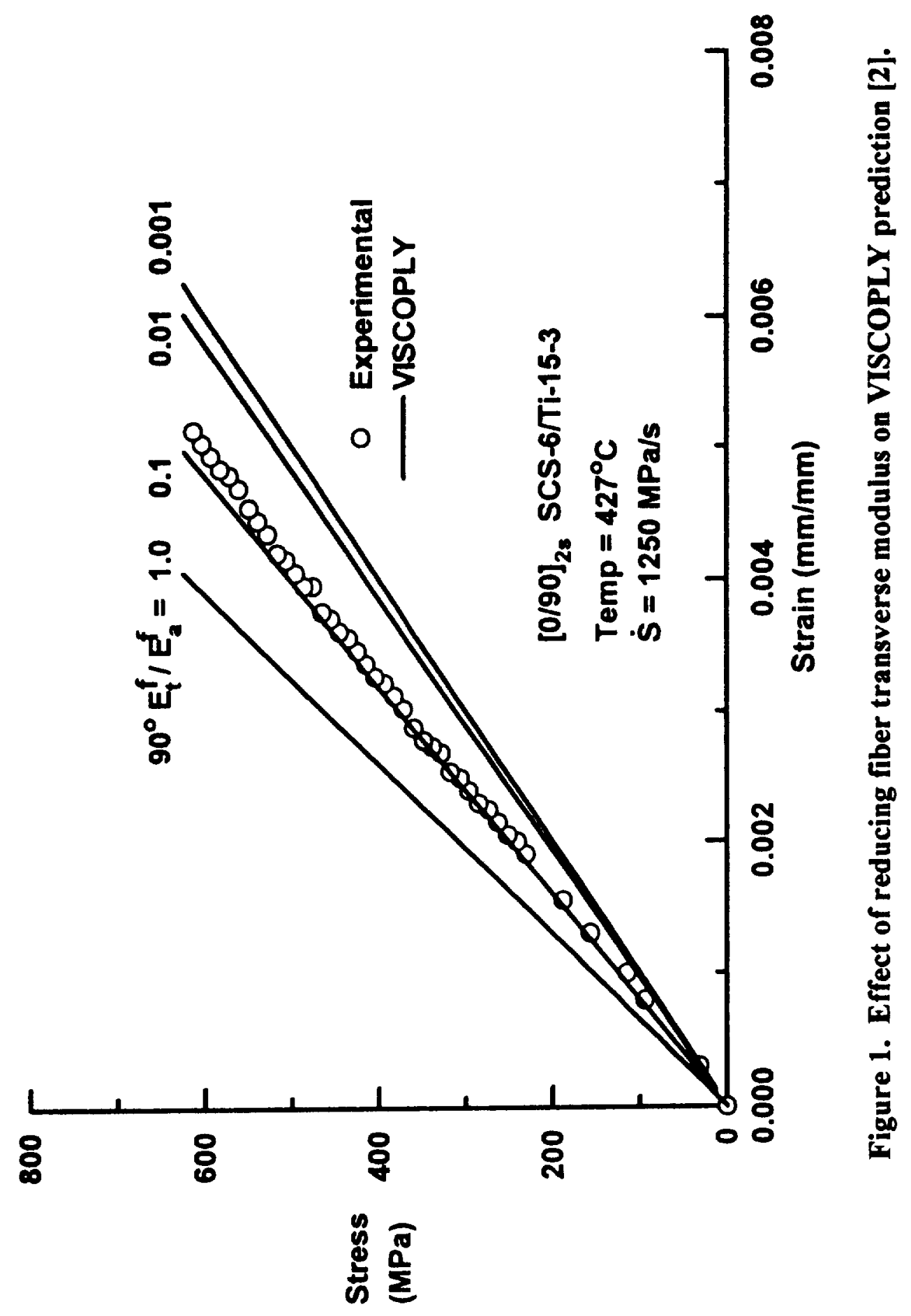




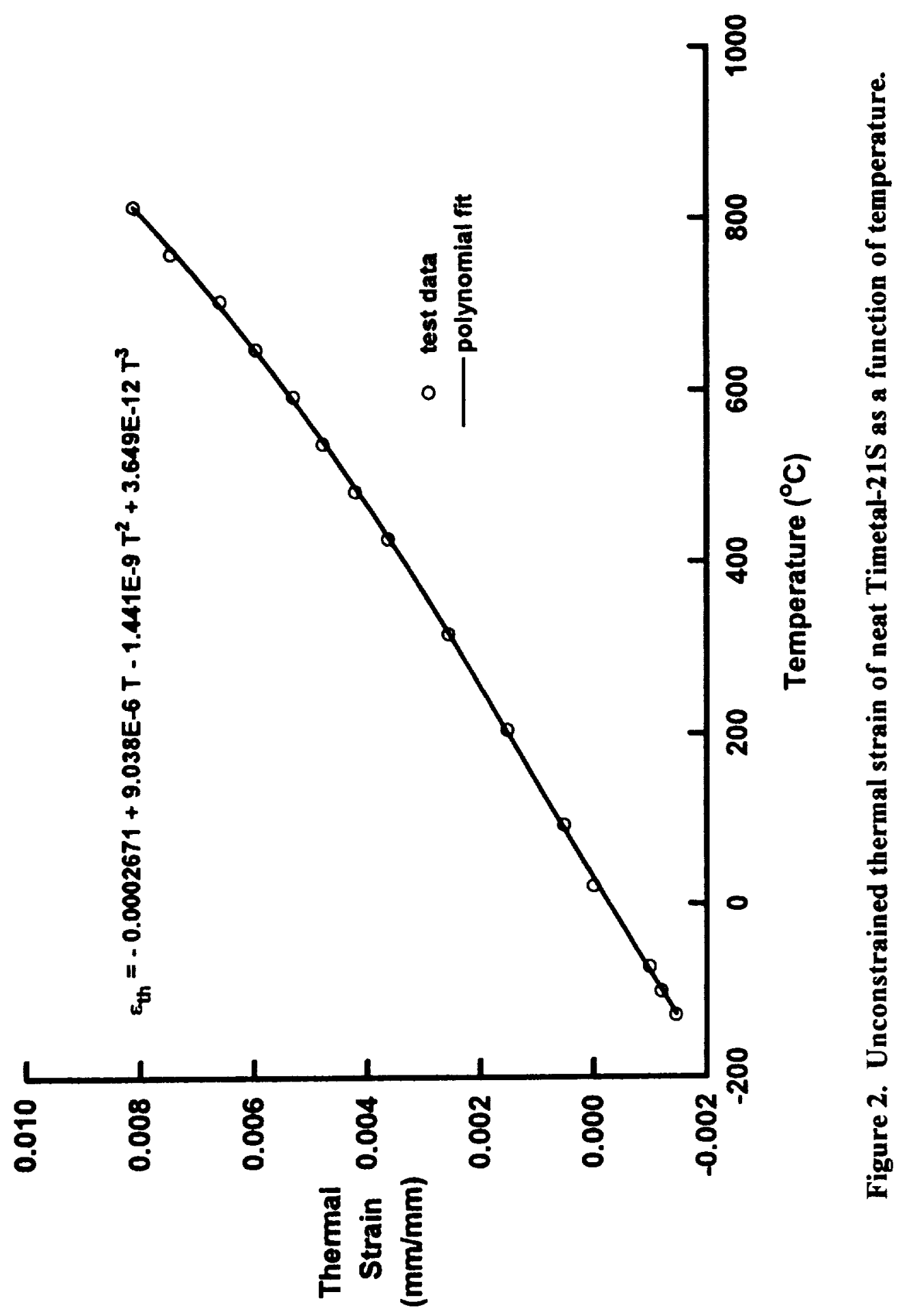




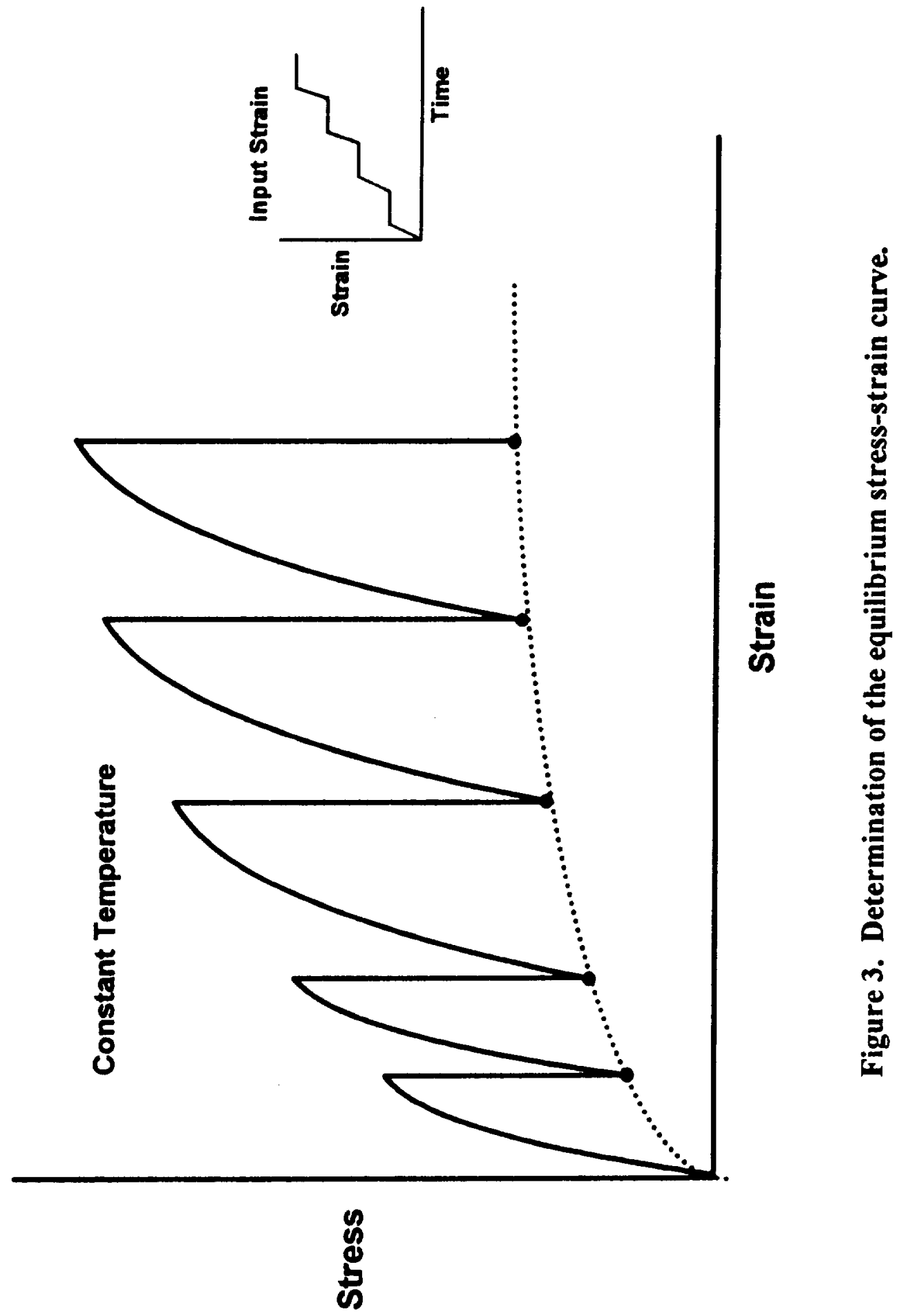



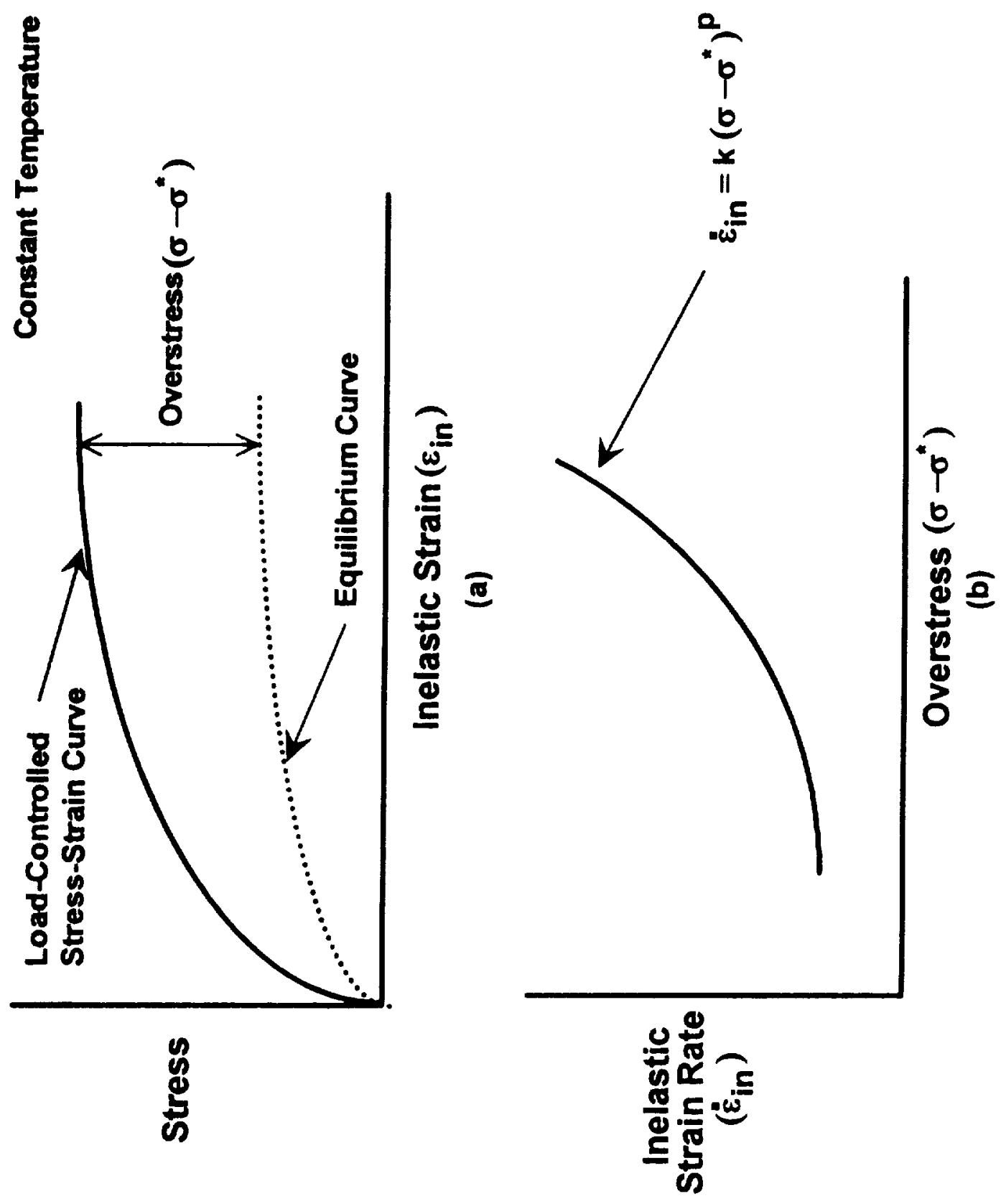

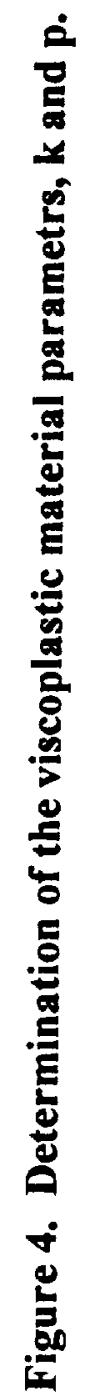




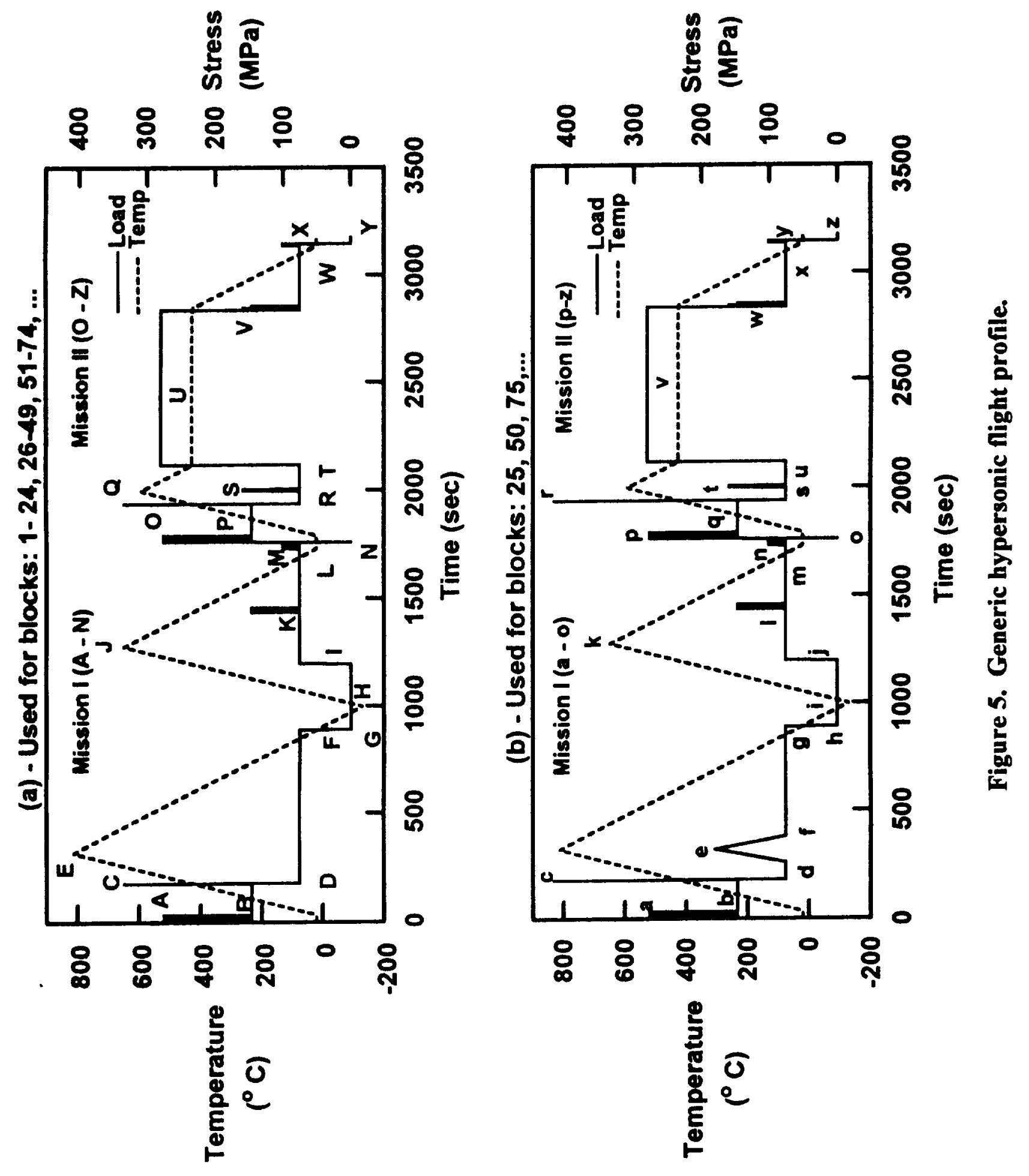




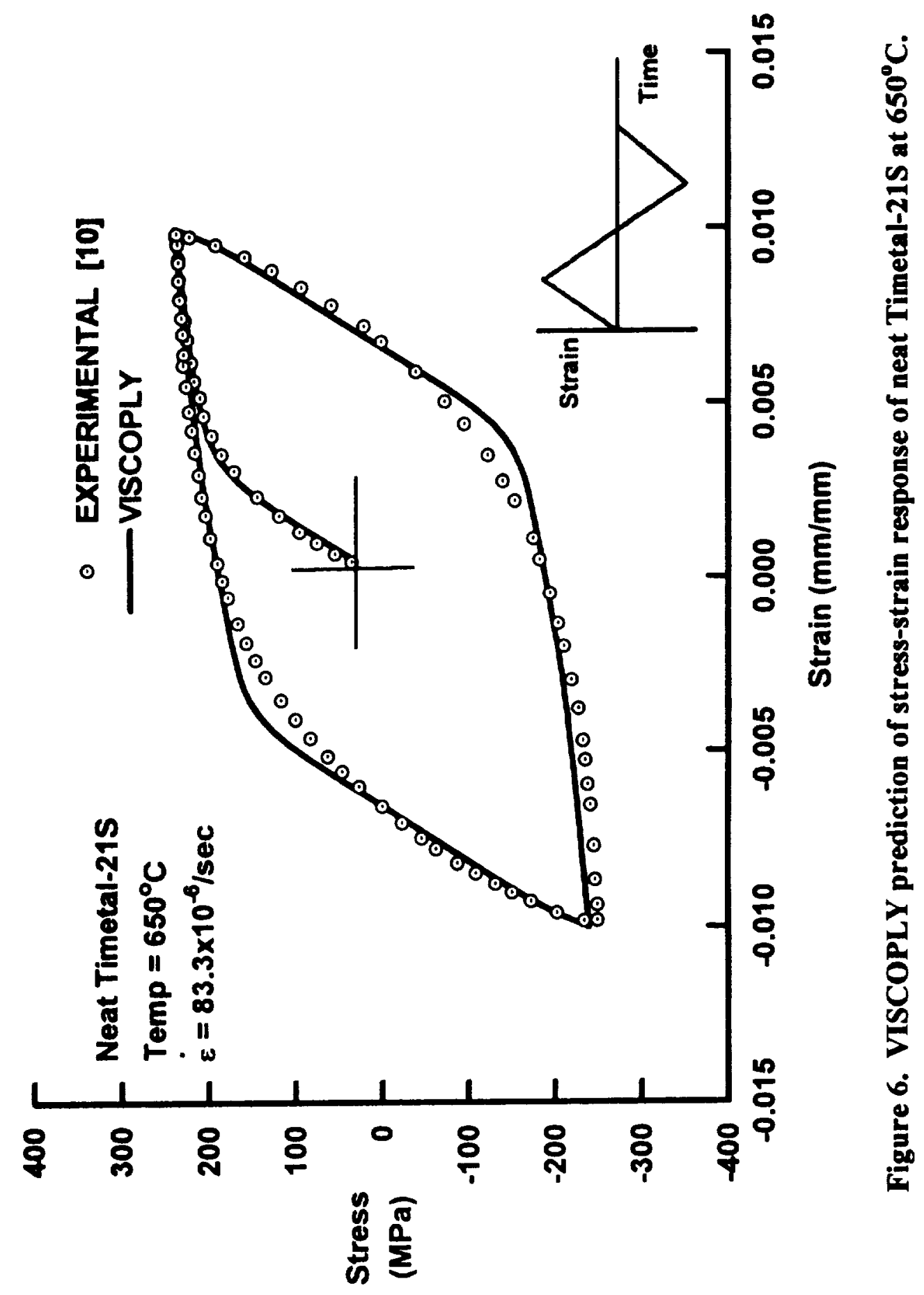




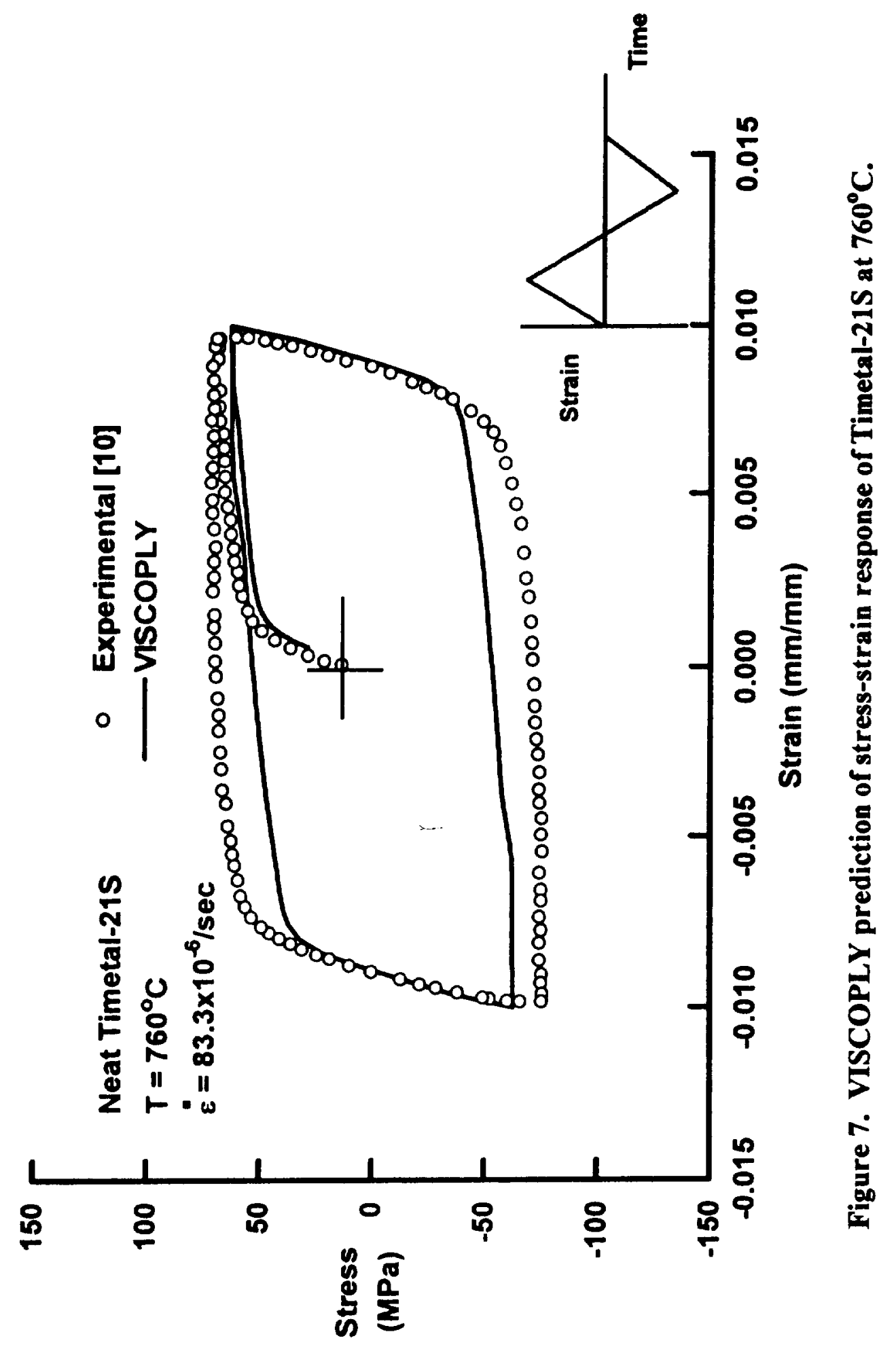




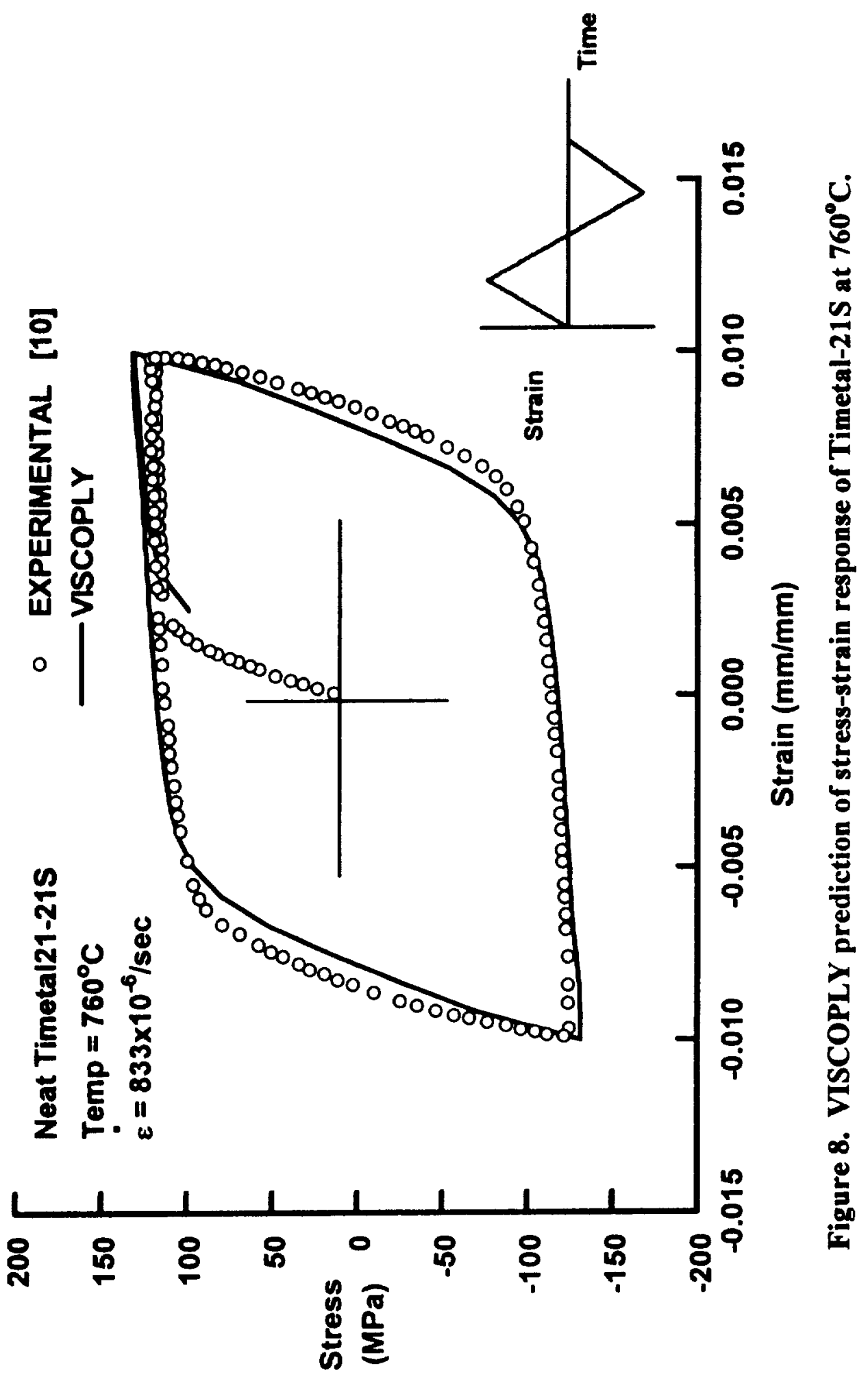




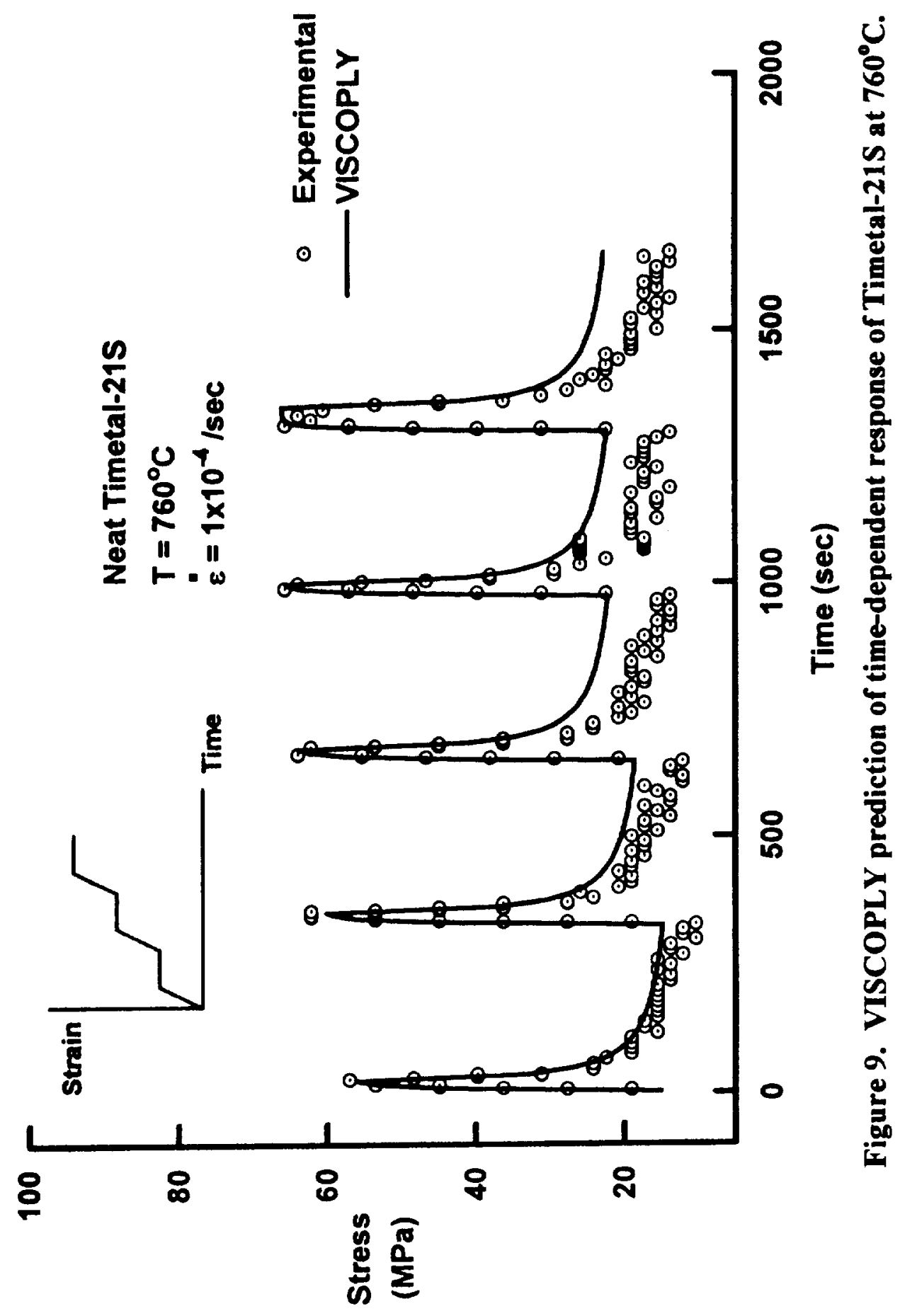




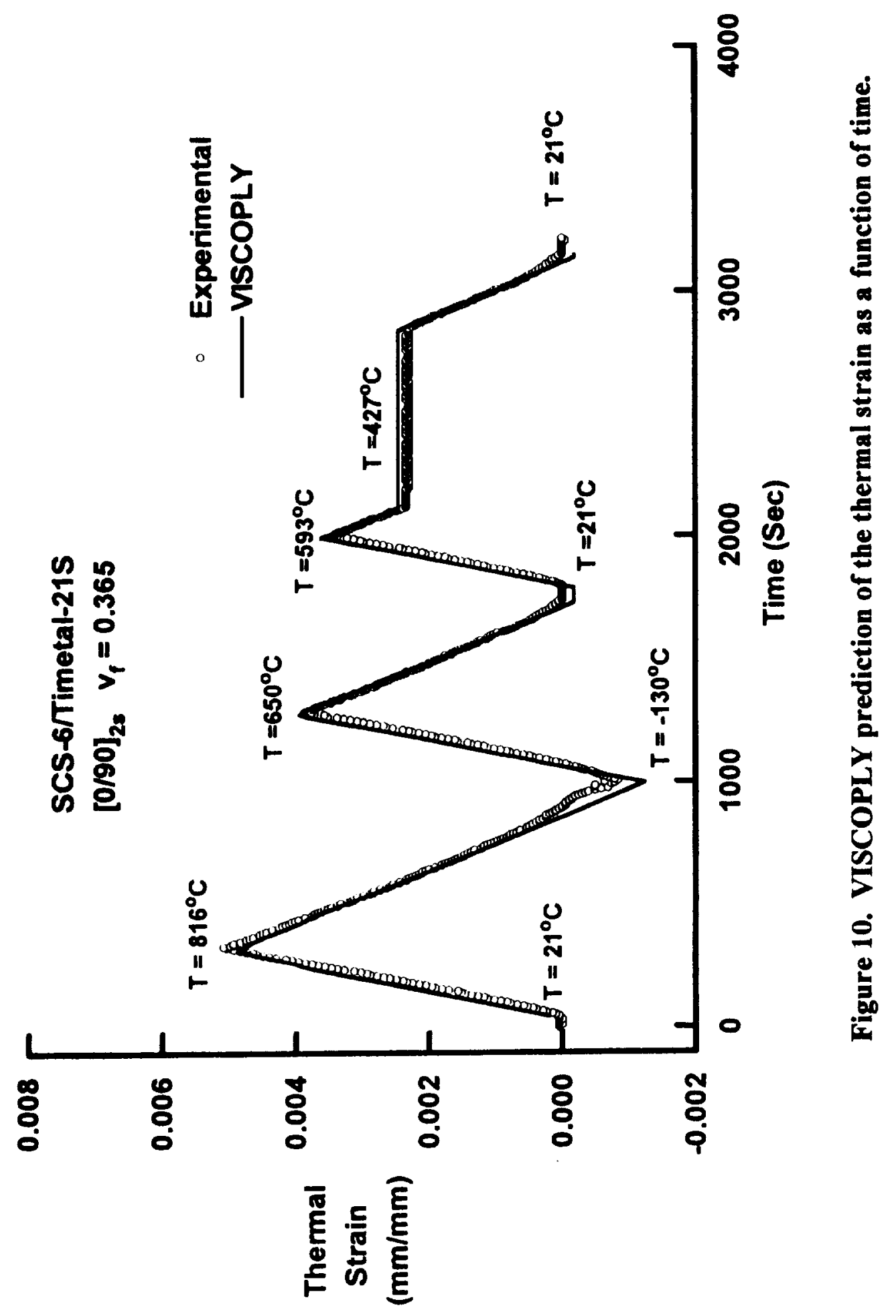




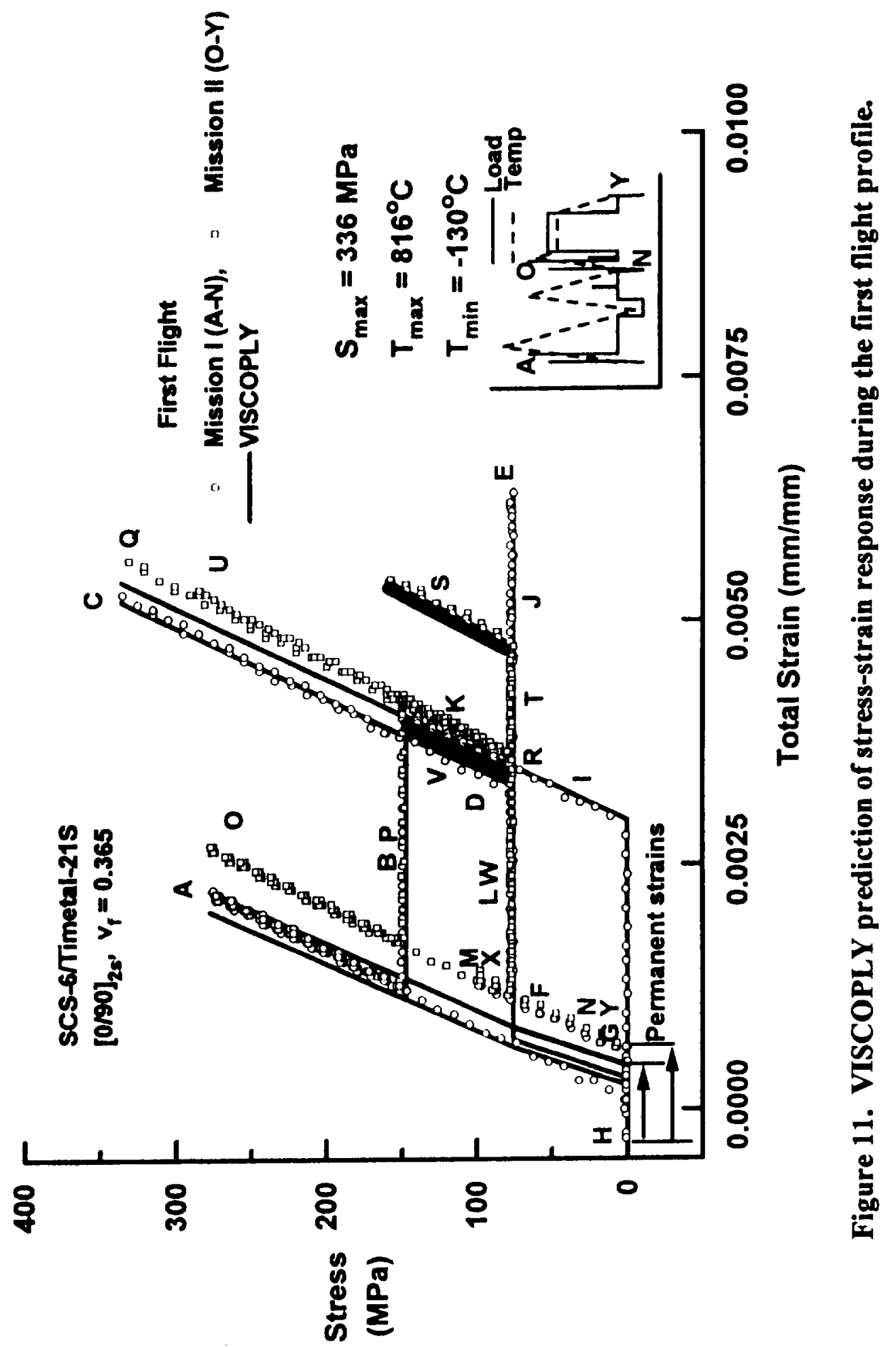




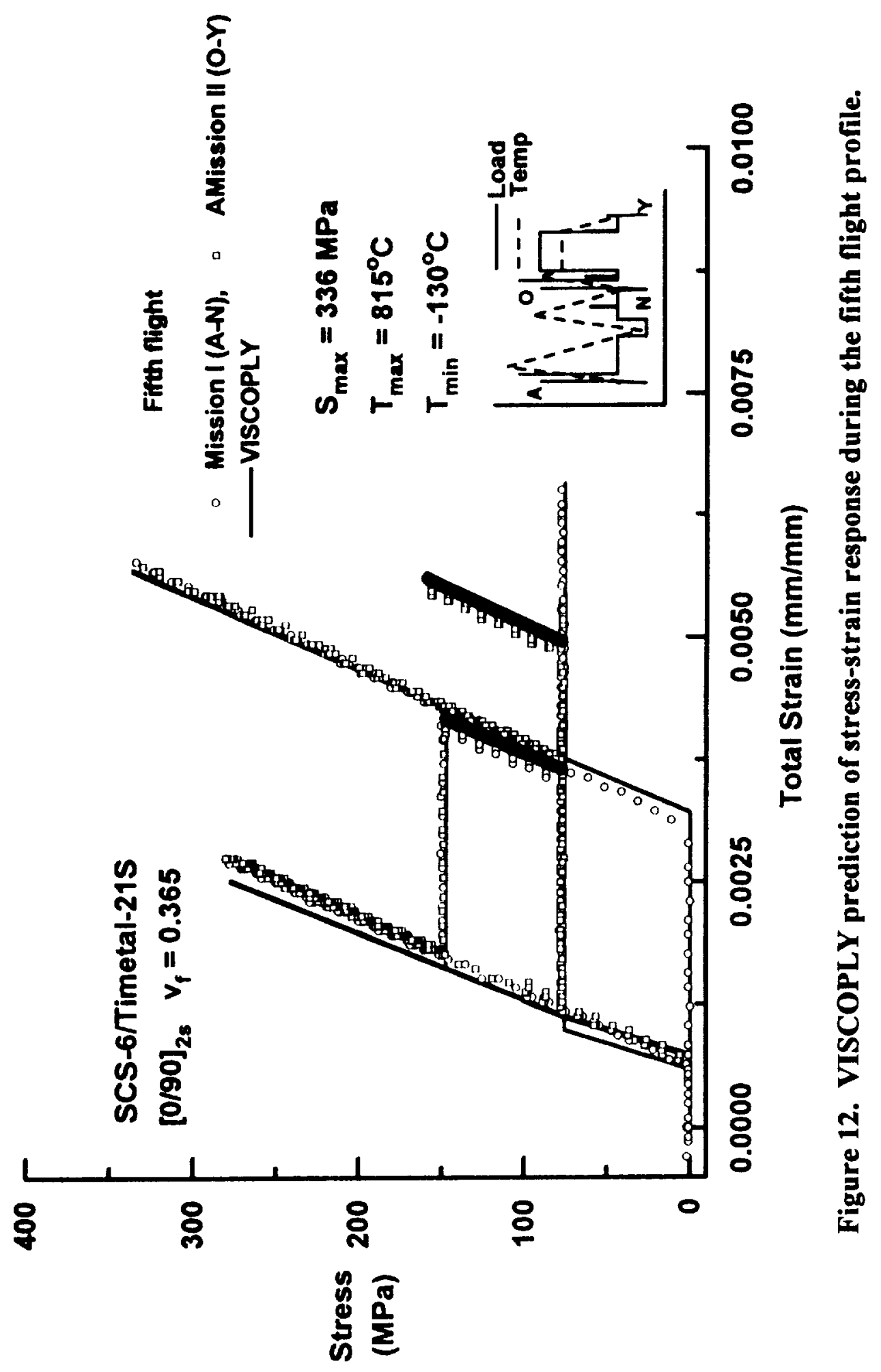




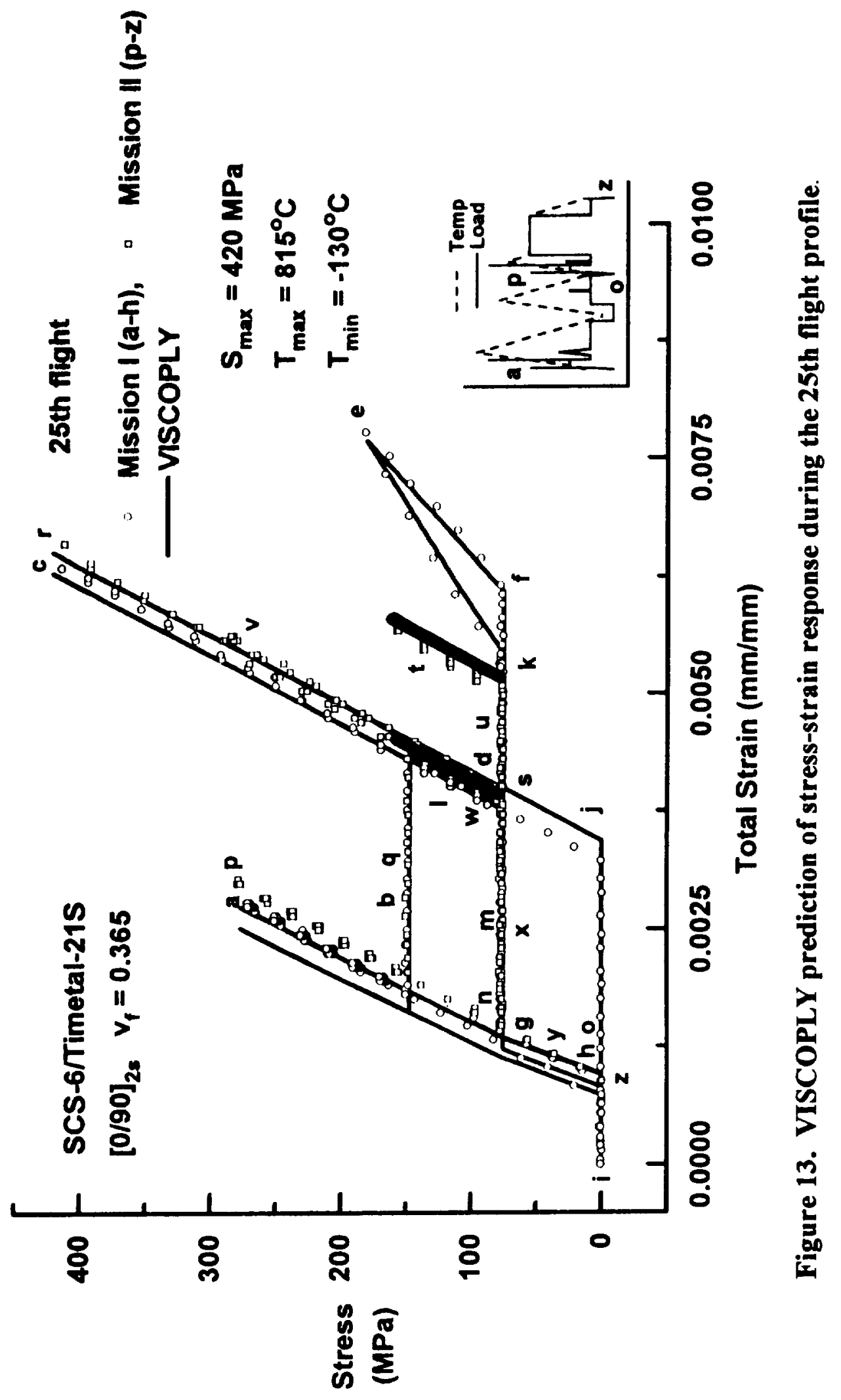




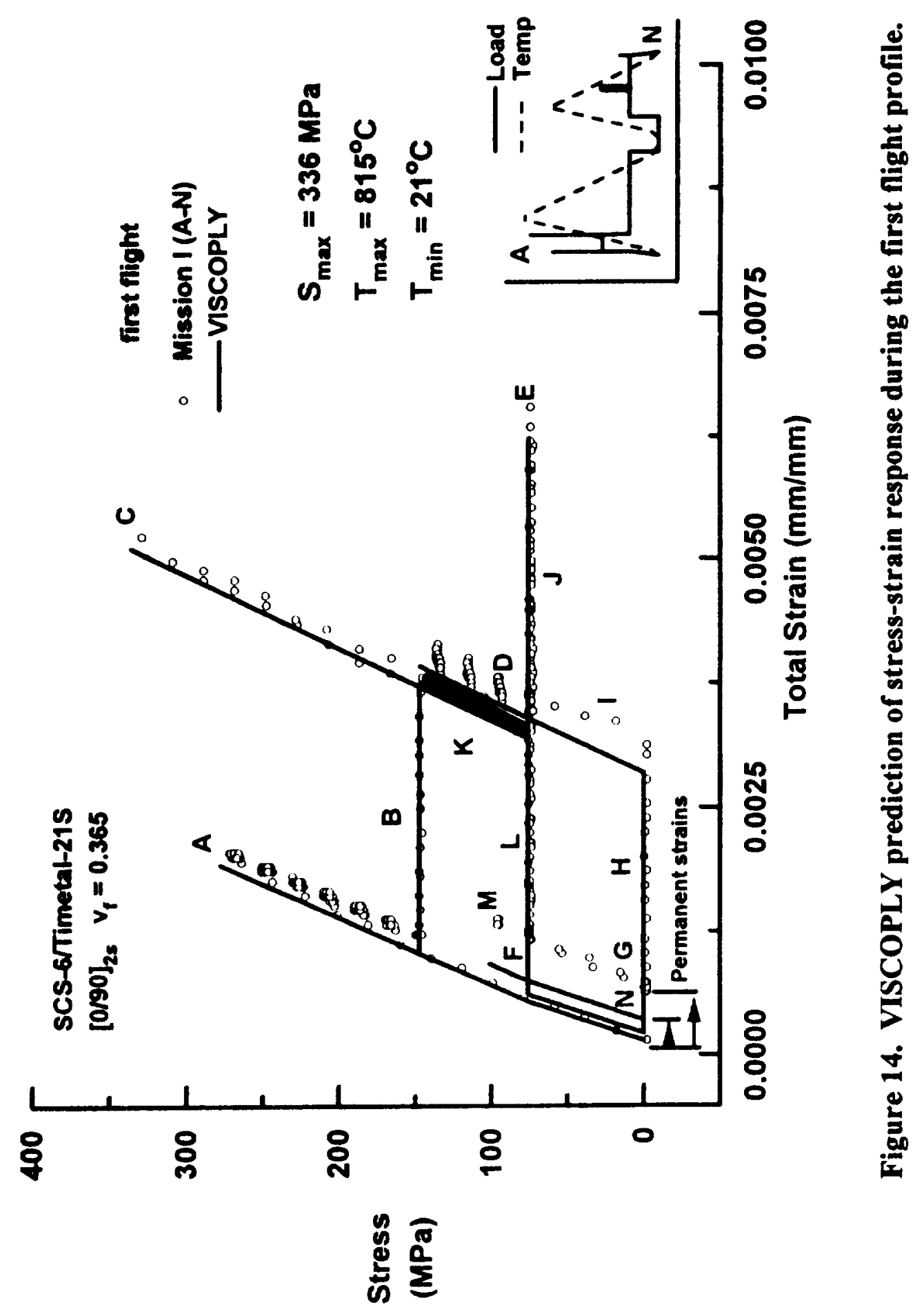




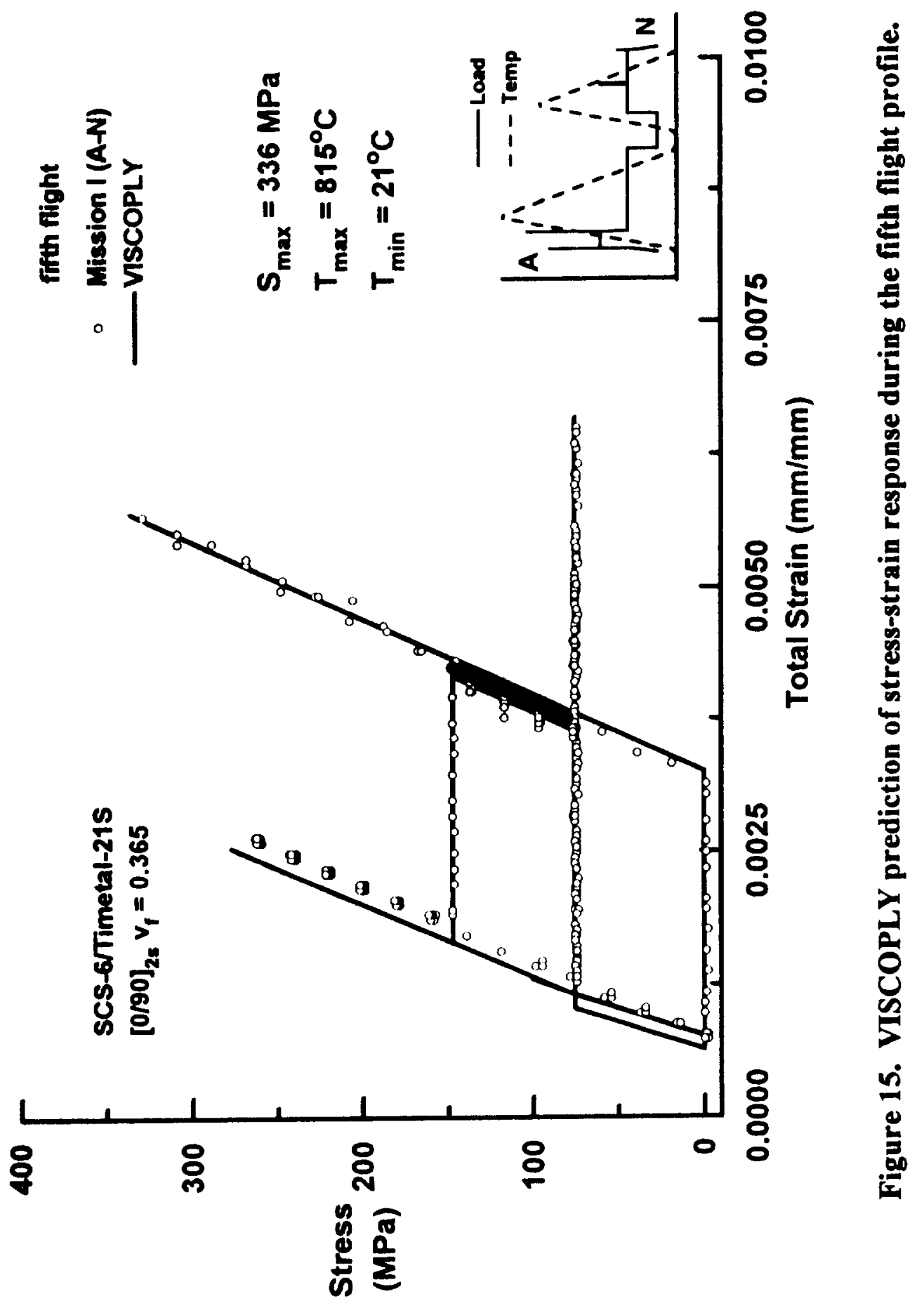




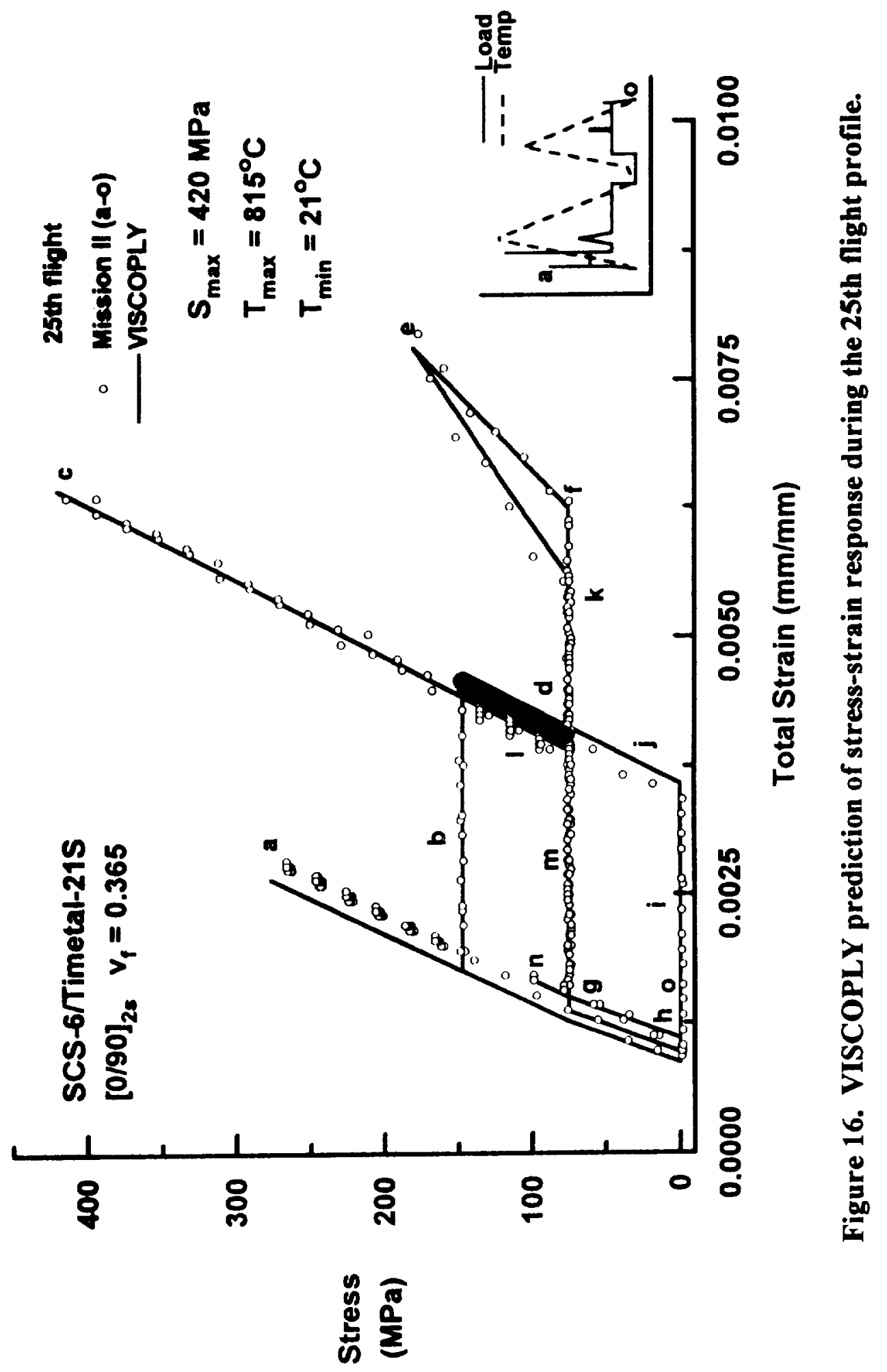




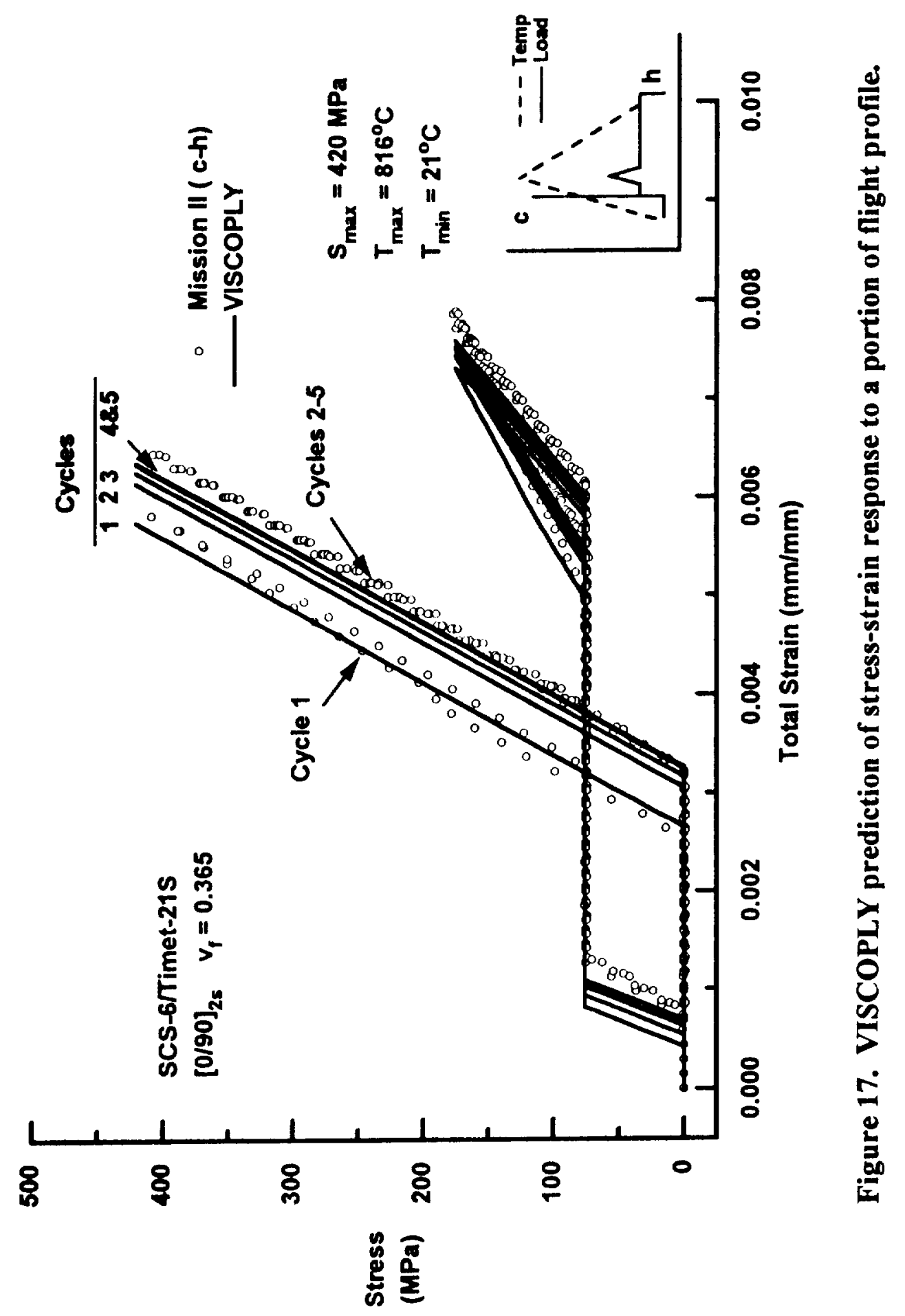




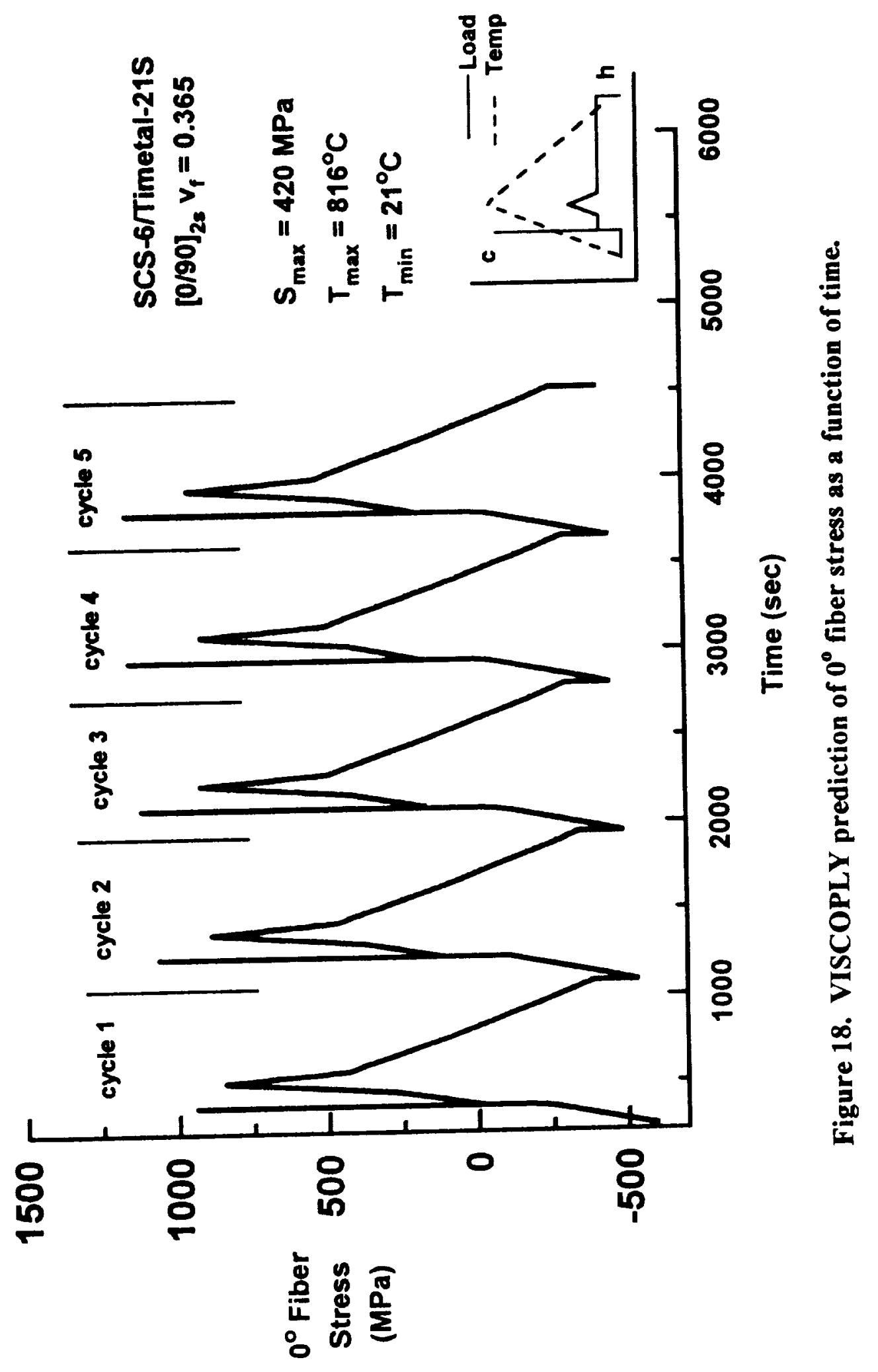





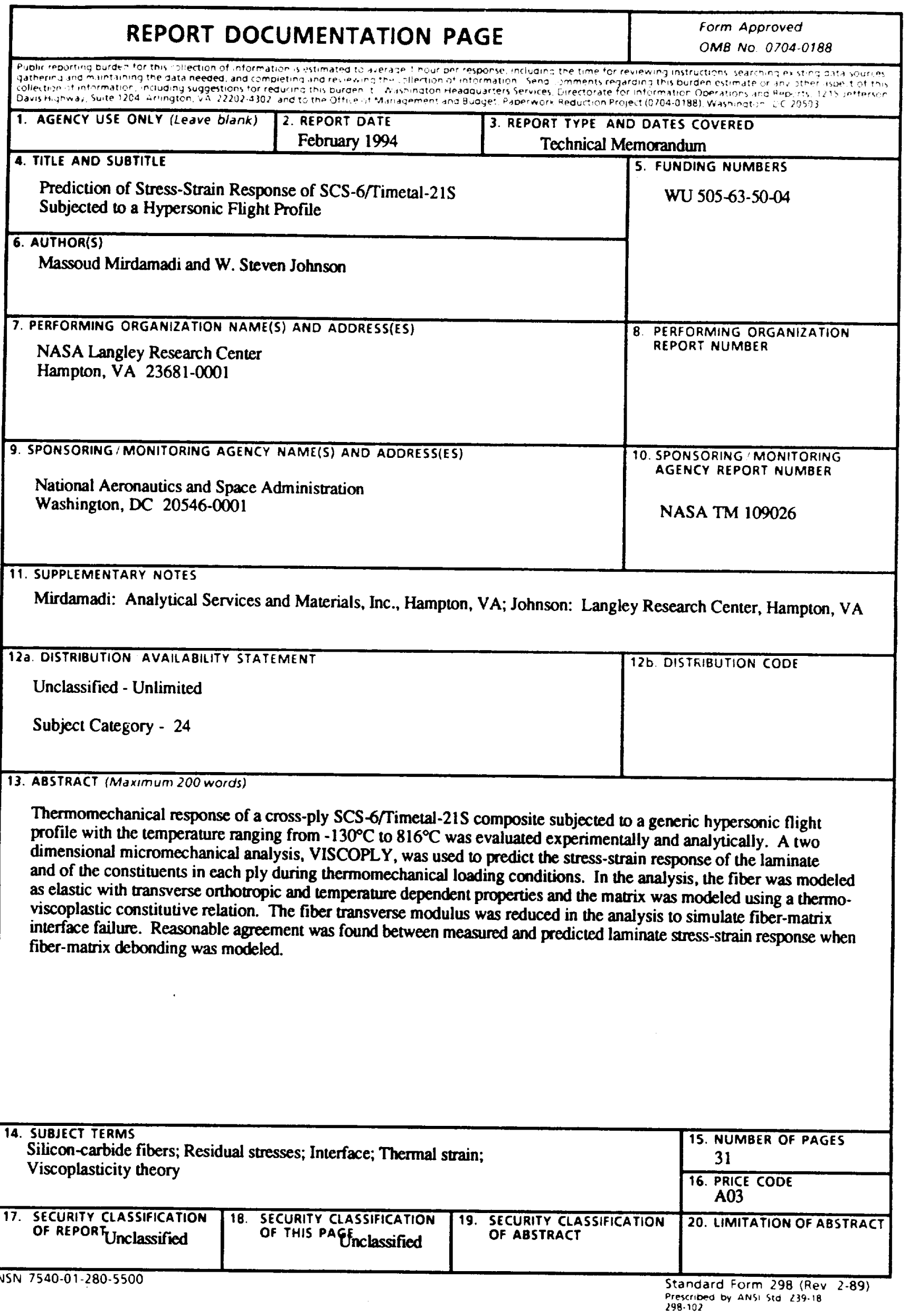

